\title{
Твердость главных минералов апатит-нефелиновых руд хибинских месторождений
}

\author{
Нерадовский Ю.Н., Компанченко А.А., Мирошникова Я.А. \\ Геологический институт КНЦ РАН, Anатиты, komp-alena@yandex.ru
}

\begin{abstract}
Аннотация. В работе приводятся данные исследования твердости главных минералов апатитнефелиновых руд хибинских месторождений: апатита, нефелина, альбита, микроклина, эгирина, титанита и натролита. В пределах месторождений Хибин установлены разные по минеральному составу и текстурным особенностям типы руд. Твердость минерала является одним из ключевых свойств, которые влияют на процессы рудоподготовки и дальнейшее извлечение полезных компонентов из руды. Измерения проводились на микротвердометре ПТМ-3 методом Виккерса. Исследования показали, что апатит является наименее твердым и наиболее хрупким минералом среди всех вышеперечисленных, следовательно, необходимо корректировать условия дробления и измельчения в зависимости от типа поступивших на рудоподготовку руд.
\end{abstract}

Ключевые слова: апатит, нефелин, твердость, Хибины, Кольский регион.

\section{Hardness of the main minerals of the Khibiny apatite-nepheline ores}

\author{
Neradovsky Yu.N., Kompanchenko A.A., Miroshnikova Ya.A. \\ Geological institute KSC RAS, Apatity, komp-alena@yandex.ru
}

\begin{abstract}
The paper shows results of hardness study of the main apatite-nepheline ores minerals of the Khibiny deposits: apatite, nepheline, albite, microcline, aegirine, titanite, and natrolite. Within the Khibiny deposits, different types of ores have been established in terms of mineral composition and texture characteristics. The hardness of the mineral is one of the key properties that affect the processes of ore preparation and further extraction of useful components from the ore. The measurements have been carried out on hardness testing PMT-3 by Vickers method. Studies have shown that apatite is the least solid and the most fragile mineral among all of the above. Therefore, it is necessary to adjust the conditions of crushing and grinding depending on the type of ore received for ore preparation.

Key words: apatite, nepheline, hardness, Khibiny, Kola region.
\end{abstract}

\section{Введение}

В статье приведены данные о микротвердости (твердости микровдавливания, далее - твердости) главных минералов Хибинских апатит-нефелиновых руд, измеренной на приборе ПМТ-3 по методу Виккерса. Ранее таких исследований не выполнялось. Твердость является одной из основных констант минералов, характеризующих их физические свойства. Это сложное интегральное свойство, зависящее как от кристаллохимических и физико-химических (типа кристаллической структуры минерала, валентности, химических связей и пр.), так и от механических факторов, присущих любому твердому телу (упругость, хрупкость, пластичность и др.). Минералы, как и все твердые кристаллические тела, обладают анизотропией физических свойств (электрических, оптических и пр.), в том числе и анизотропией твердости (Потапков, 1957; Лебедева, 1977), что имеет большое значение в различных технологических процессах.

Твердость минералов, составляющих руду - одно из наиболее важных свойств, которое определяет прочность и влияет на процессы переработки и обогащения руд, а также на скорость износа оборудования фабрик. При эксплуатации месторождений в рудоподготовке важнейшим этапом является дезинтеграция руды с целью раскрытия минералов, поскольку это наиболее дорогой комплекс процессов вследствие их высокой энергоемкости (до 60 \% стоимости обогащения) (Изоитко, 1997). Для оптимизации процесса дезинтеграции сложных по минеральному составу руд необходимо тщательно следить за измельчаемостью, которая непосредственно связана с соотношением минералов разной твердости (Кононов, Бакшеев, 2004). Это позволит избежать переизмельчения руды, т.е. увеличения количества частиц нежелательной крупности, снижающих эффективность обогащения, а также снизить энергозатраты. 
Хибинские апатит-нефелиновые руды являются многокомпонентными и соотношение минералов различной твердости в разных месторождениях может изменяться, в связи с этим изменяется и измельчаемость руд, поэтому необходимо корректировать условия измельчения.

\section{Методы исследования}

Для изучения твердости использованы минералы из коллекции авторов и концентраты, предоставленные ОСТМ ИХТРЭМС Т.П. Белогуровой. Порошки минералов хибинских апатитнефелиновых руд смешивались с эпоксидным клеем и из смеси изготавливались искусственные аншлифы. Изучение минералов и первичная документация препаратов проводилась в отраженном поляризованном свете на поляризационном микроскопе Axioplan c блоком видеорегистрации. Качественный химический анализ и изучение фазовой и внутрифазовой неоднородности минералов проводились на сканирующем электронном микроскопе Leo 1450 с энергодисперсионным анализатором Bruker X-Flash 5010 (аналитик А.В. Базай, ГИ КНЦ РАН). Значения твердости минералов получены на микротвердометре ПМТ-3 при нагрузке 50 г.

\section{Краткая характеристика объекта исследования}

Апатитовые месторождения Хибин приурочены к йиолит-уртитам и рисчорритам и располагаются в виде прерывистой дуги, согласующейся с общим строением массива (Дудкин и др., 1964; Kogarko, 2018).

По вещественному составу и текстурным особенностям выделяют следующие типы руд (по Дудкин и др., 1964): 1. Апатитовая порода пятнистой текстуры; 2. Полосчатая, пятнистополосчатая апатит-нефелиновая порода; 3. Линзовидно-полосчатая апатит-нефелиновая порода; 4. Апатитовая брекчия; 5. Крупноблоковая порода; 6. Мелкоблоковая порода; 7. Уртит с апатитом; 8. Апатит-нефелиновые породы на контакте со среднезернистыми эгириновыми нефелиновыми сиенитами.

Данные типы руд отличаются по минеральному составу. Например, пятнисто-полосчатые породы отличаются от пятнистых более высоким содержанием нефелина, что может быть обусловлено и присутствием в них отдельных уртитовых прослоев. Кроме того, по сравнению со всеми апатит-нефелиновыми породами, пятнисто-полосчатые породы отличаются самыми высокими содержаниями апатита и низким - темноцветных минералов. Менее богаты апатитом линзовиднополосчатые апатит-нефелиновые породы. Полосчатые породы по составу очень близки к породам этого типа, но содержат больше апатита.

Каждый минерал в этих рудах обладает своими определенными свойствами, которые будут вносить коррективы в процесс переработки руды. Одним из таких свойств и будет твердость.

Данная работа нацелена на изучение твердости главных минералов из разных месторождений, текстурных и вещественных типов апатит-нефелиновых руд; установление различий твердости в минералах и влияния этого параметра на технологические свойства; зависимости микротвердости от типа руды, химического состава минерала и наличия твердофазных или газово-жидких включений. Результаты планируется использовать для выработки рекомендаций более рационального обогащения руд.

\section{Результаты исследования}

На первом этапе задача состояла в экспериментальном опробовании методики измерения твердости (далее твердости) силикатных, фосфатных и других «нерудных» минералов Хибинских руд методом Викерса на приборе ПМТ-3 (Методы минералогических исследований, 1985). Все минералы предварительно были исследованы и подтверждены с помощью сканирующей электронной микроскопии и качественной оценки состава. Измерения, выполненные по стандартной методике, позволили положительно оценить ее применение для решения поставленных задач.

\section{Anamum}

Согласно литературным данным (Дудкин и др., 1964; Kogarko, 2019) и номенклатуре минералов группы апатита (Pasero et al., 2010), минерал группы апатита Хибинских месторождений отно- 

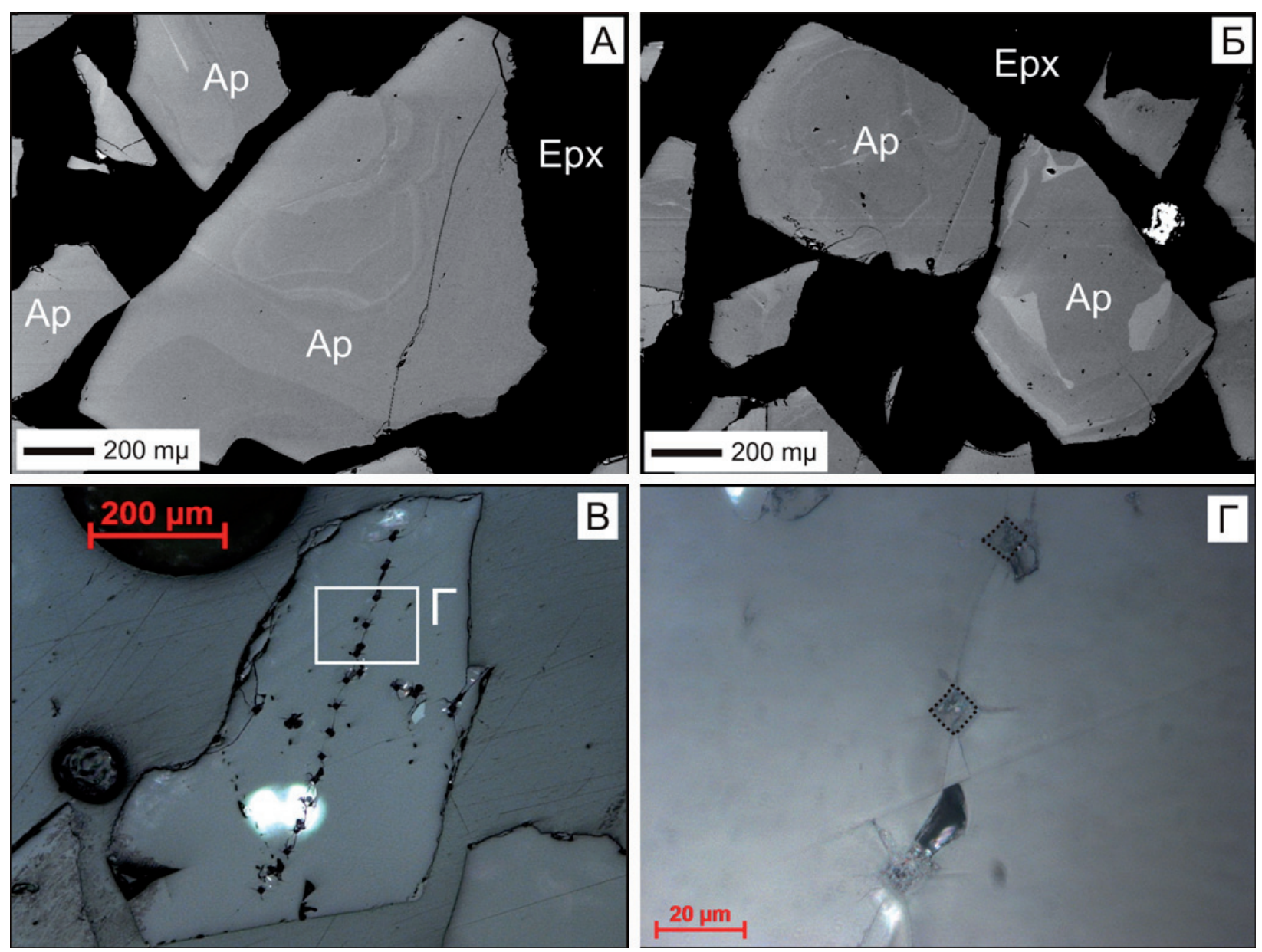

Рис. 1. Внутрифазовая неоднородность в апатите (А-Б, BSE снимки) и цепочка измерений твердости в зерне апатита (В-Г, снимок в отраженном поляризованном свете). Ар - апатит; Ерх - эпоксидная смола.

Fig. 1. Intraphase heterogenity in apatite (А-Б, BSE images) and points of hardness measurements in apatite grain (B- $\Gamma$, images in reflected polarized light). Ap - apatite, Epx - epoxide.

сится к фmopanamumy $C a_{5}\left(P O_{4}\right)_{3} F$. Наши данные также это подтвердили. На снимках в BSE в минерале выявляется внутрифазовая неоднородность, связанная с неравномерным распределением стронция и редкоземельных элементов (рис. 1, А-Б). В срастании с апатитом часто отмечается нефелин.

Таблица 1. Значения твердости главных минералов апатит-нефелиновых руд.

Table 1. Hardness of the main minerals of apatite-nepheline ore.

\begin{tabular}{|c|c|c|c|c|c|}
\hline \multirow{2}{*}{ Минерал } & \multirow{2}{*}{$\begin{array}{c}\text { Кол-во } \\
\text { изм. }\end{array}$} & \multicolumn{3}{|c|}{ Твердость, кг/мм² } & \multirow{2}{*}{$\begin{array}{c}\text { Твердость } \\
\text { по шк. Мооса }\end{array}$} \\
\hline & & Min & Max & Среднее & \\
\hline Альбит & 36 & 1145 & 1236.5 & 1190 & $6-6.5$ \\
\hline Нефелин & 36 & 1079 & 1236.5 & 1103 & $5.5-6$ \\
\hline Эгирин & 36 & 947 & 1145 & 1049 & 6 \\
\hline Титанит & 36 & 865.6 & 1236.5 & 1046 & $5-5.5$ \\
\hline Микроклин & 36 & 845 & 1145 & 930 & $6-6.5$ \\
\hline Натролит & 36 & 531.2 & 720.8 & 659 & $5-5.5$ \\
\hline Фторапатит & 48 & 430.3 & 753 & 597 & 5 \\
\hline
\end{tabular}

*данные по Handbook

Значения твердости фторапатита приведены в табл. 1. Полученные величины сильно варьируют, при этом на поверхности минерала не виды трещины или приповерхностные газово-жидкие включения. Форма отпечатка алмазной пирамидки искаженная, с вогнутыми внутрь краями. Мине- 
рал сильно крошится, выкалывается, по краям отпечатка четко видны трещины (рис.1, В-Г). Значение твердости фторапатита, полученное нами, близко к ранее опубликованным значениям (Дудкин и др., 1964).

\section{нефелин}

В нефелине не выявлена какая-либо внутрифазовая неоднородность (рис. 2, А-Б), однако по нефелину широко развивается вторичный минерал - натролит. Также в виде мелких включений в нефелине отмечен апатит.

Значения твердости минерала довольно выдержаны, форма отпечатка изометричная, крупные трещины наблюдаются довольно редко, минерал практически не крошится (рис. 2, А-Б). Твердость нефелина практически в два раза превышает твердость апатита (табл. 1).
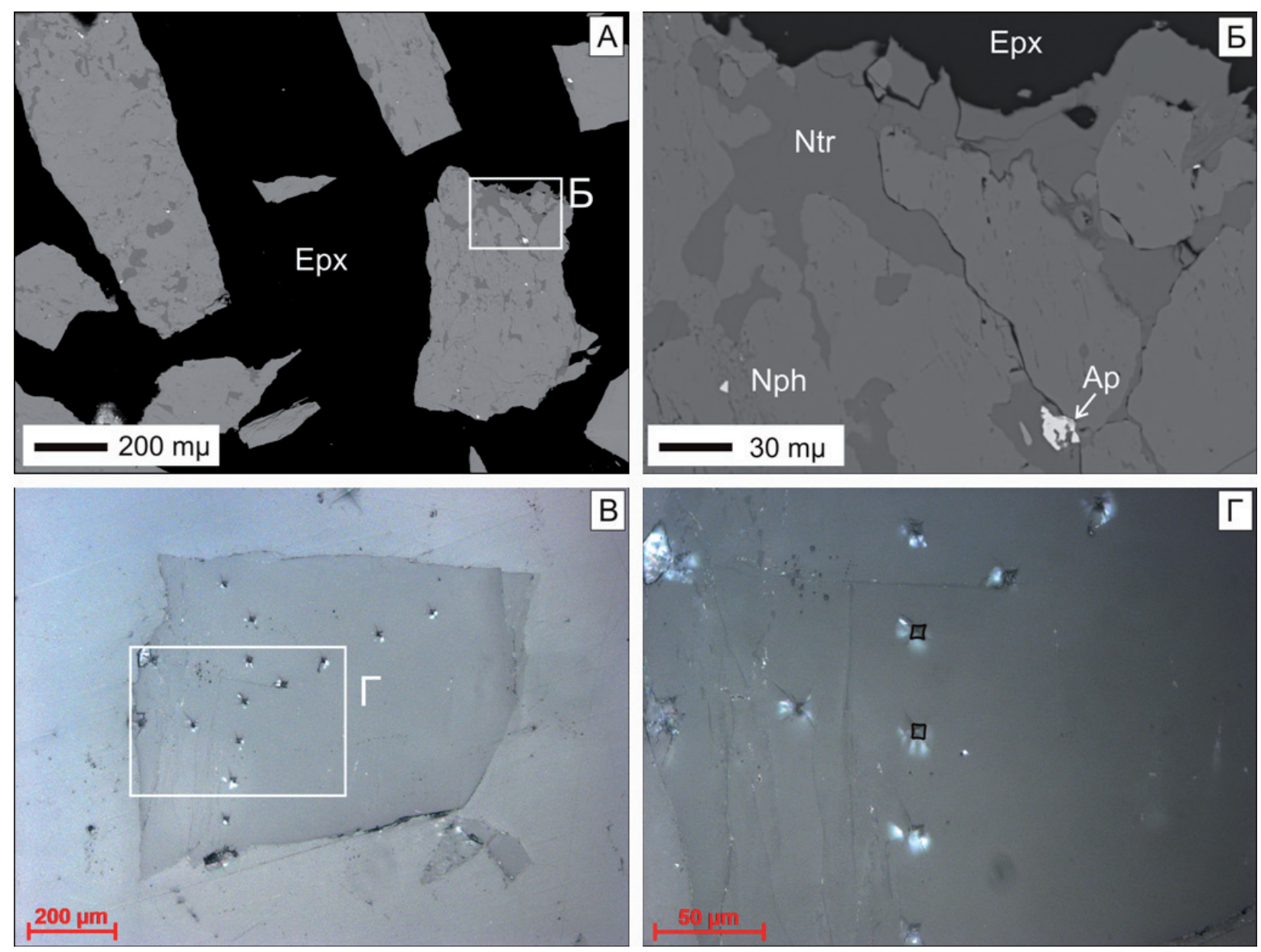

Рис. 2. Фазовая и внутрифазовая неоднородность в нефелине (А-Б, BSE снимки) и цепочка измерений твердости в зерне нефелина (В-Г, снимок в отраженном поляризованном свете). Ар - апатит; Ерх - эпоксидная смола; Nph - нефелин; Ntr - натролит.

Fig. 1. Phase and intraphase heterogenity in nepheline (А-Б, BSE images) and points of hardness measurements in nepheline grain (B- $\Gamma$, images in reflected polarized light). Ap - apatite, Epx - epoxide; Nph - nepheline; Ntr - natrolite.

\section{Другие минералы}

Также значения твердости были получены для альбита, микроклина, эгирина, титанита и натролита (табл. 1). Для некоторых минералов наблюдалась зависимость значения твердости от плоскости среза зерна (титанит и эгирин). Альбит, микроклин и натролит не проявляют какой-либо внутрифазовой неоднородности, включения других минералов в них достаточно редки. В титаните и эгирине выявлена слабая зональность. В титаните она связанная с неоднородным распределением $\mathrm{Fe}, \mathrm{Nb}$ и Zr. Также в титаните наблюдаются включения апатита и эгирина. В зернах эгирина 
зональность, вероятно, связана с неоднородным распределением Fе и замещающих его элементов. Поверхность срезов зерен микроклина отличалась от других минералов повышенной пористостью и трещиноватостью, в связи с чем микроклин показал несколько меньшую твердость, чем другие полевые шпаты.

\section{Заключение}

В большинстве минералогических справочников (например, Handbook) и интернет-ресурсах (mindat, webmineral и др.), твердость минералов приводится по шкале Мооса. Для главных минералов апатит-нефелиновых руд твердость по шкале Мооса приведена в таблице1. Реальные же значения микротвердости силикатов приводятся крайне редко, а подобные измерения для всех главных минералов хибинских апатит-нефелиновых руд нами не найдено вовсе.

В таблице 1 минералы расставлены от более твердых к менее, согласно нашим исследованиям. Фторапатит обладает наименьшей твердостью по сравнению с другими минералами, слагающими апатит-нефелиновые руды. К тому же, он наиболее хрупкий. Следовательно, при проведении рудоподготовки (дроблении и измельчении), фторапатит будет разрушаться быстрее остальных минералов не только при контакте с оборудованием фабрик, но и при контакте минералов внутри дробилок и мельниц. Как следствие, фторапатит будет переизмельчатся, из-за чего увеличатся его потери. В качестве вывода можно заключить, что разные типы руд, с разным содержанием апатита, нефелина и других минералов, должны дробиться и измельчаться в течение разного времени, чтобы уменьшить потери фторапатита и сделать его извлечение более эффективным.

\section{Литература}

1. Дудкин О.Б., Козырева Л.В., Померанцева Н.Г. Минералогия апатитовых месторождений Хибинских тундр. Л. Изд-во: Наука. 1964. 236 с.

2. Изоитко В.М. Технологическая минералогия и оценка руд. СПб. Изд-во: Наука. 1997. 582 с.

3. Кононов О.В., Бакшеев И.А. Курс технологической минералогии. Учебное пособие. М. Изд-во: МГУ. 2004. $203 \mathrm{c}$.

4. Лебедева С.И. Микротвердость минералов. М. Изд-во: Недра. 1977. 118 с.

5. Методы минералогических исследований: Справочник (под. ред. А.И.Гинзбурга). М. Изд-во: Недра. 1985. 480 c.

6. Потапков И.А. К теории анизотропии кубических кристаллов // Докл. АН СССР. 1957. Т. 117. №6. C. 965-966.

7. Anthony J.W., Bideaux R.A., Bladh K.W., Nichols C.M., Eds. Handbook of Mineralogy. Mineralogical Society of America, Chantilly, VA 20151-1110, USA.

8. Pasero, M.; Kampf, A.R.; Ferraris, C.; Pekov, I.V.; Rakovan, J.; White, T.J. Nomenclature of the apatite supergroup minerals // Eur. J. Miner. 2010. № 22. P. 163-179. 